\title{
Inhibition of autoimmune Th17 cell responses by pain killer ketamine
}

\author{
Jeong-Eun Lee ${ }^{1,2, *}$, Jung-Man Lee ${ }^{3, *}$, Young-Jun Park ${ }^{1}$, Byung-Seok Kim,2, Young- \\ Tae Jeon ${ }^{4,5}$ and Yeonseok Chung ${ }^{1,2}$ \\ ${ }^{1}$ Laboratory of Immune Regulation, Institute of Pharmaceutical Sciences and College of Pharmacy, Seoul National University, \\ Seoul, Republic of Korea \\ 2 BK21 plus program, College of Pharmacy, Seoul National University, Seoul, Republic of Korea \\ ${ }^{3}$ Department of Anesthesiology and Pain Medicine, SMG-SNU Boramae Medical Center, Seoul, Republic of Korea \\ ${ }^{4}$ Department of Anesthesiology and Pain Medicine, College of Medicine, Seoul National University, Seoul, Republic of Korea \\ 5 Department of Anesthesiology and Pain Medicine, College of Medicine, Seoul National University Bundang Hospital, \\ Seongnam, Republic of Korea \\ * These authors have equally contributed to this work \\ Correspondence to: Yeonseok Chung, email: yeonseok@snu.ac.kr \\ Young-Tae Jeon, email: ytjeon@snubh.org
}

Keywords: ketamine, Th17 cell, STAT3, IL-21, autoimmunity, Immunology and Microbiology Section, Immune response, Immunity Received: April 04, $2017 \quad$ Accepted: May 23, $2017 \quad$ Published: May 31, 2017

Copyright: Lee et al. This is an open-access article distributed under the terms of the Creative Commons Attribution License 3.0 (CC BY 3.0), which permits unrestricted use, distribution, and reproduction in any medium, provided the original author and source are credited.

\section{ABSTRACT}

Ketamine is widely used in animals and humans as a systemic anesthetic. Although several immune-modulatory functions of ketamine have been reported, the effects of ketamine on the differentiation of Th17 cell are unknown. We found that ketamine significantly diminished the frequency of IL-17-producers among CD4+ T cells stimulated under Th17-skewing conditions. Mechanistic studies showed that ketamine had little effect on the production of Th17-inducing cytokines by dendritic cells and the proliferation of $\mathrm{T}$ cells in response to anti-CD3; however it significantly hampered IL-21 expression as well as STAT3 phosphorylation in T cells upon IL-6 stimulation. Moreover, MOG-reactive $\mathrm{CD}^{+} \mathrm{T}$ cells expanded in the presence of ketamine produced reduced amounts of Th17 cytokines, leading to diminished EAE severity when transferred into TCR $\beta$-deficient mice in comparison to those treated with vehicle. These findings demonstrate that ketamine suppresses autoimmune Th17 cell responses by inhibiting the differentiation as well as the reactivation of Th17 cells.

\section{INTRODUCTION}

Immuno-modulatory effects of various anesthetics have been extensively studied in recent years. For example, volatile anesthetics have been proven to increase tumor formation, whereas propofol has been shown to exert protective effects in preclinical studies [1]. In addition, sevoflurane has been reported to inhibit $\mathrm{T}$ cell activation and ameliorate clinical symptoms of experimental autoimmune encephalomyelitis (EAE), an animal model of human multiple sclerosis [2]. When used as an anesthetic in patients during surgery, propofol exerts an immuno-protective role by promoting Th1 cell differentiation [3]. Lidocaine is another example that has been reported to inhibit Th1 cell response by suppressing the secretion of pro-inflammatory cytokines in dendritic cells [4].

Ketamine is widely used as an anesthetic and analgesic for general anesthesia and chronic pain management [5]. The primary mechanism of action of ketamine is through the noncompetitive antagonism of the N-methyl D-aspartic acid (NMDA) receptor, releasing tonic inhibition from cortical $\gamma$-aminobutyric acid-ergic (GABAergic) interneurons on output neurons [6]. By stimulating the mTOR signaling pathway, ketamine can also prolong anti-depressant effects via the increased connectivities of neuronal synapses [7]. In addition to its well-known function as an anesthetic, ketamine has been shown to exert immuno-regulatory effects. For instance, ketamine inhibited the priming of Th1-mediated immune 
response by suppressing maturation of bone marrowderived dendritic cells (BMDC) [8]. However, its effects on other Th subsets including Th17 remain elusive.

IL-17-producing $\mathrm{T}$ helper cell subset (Th17) has emerged as a crucial player in the adaptive immune system during the last decade [9]. Th17 cell differentiation is initiated by the activation of STAT3 in the presence of IL- 6 and transforming growth factor- $\beta$ (TGF- $\beta)$ [10], which induces the transcription of Th17 cell-associated genes, including Rorc, $I l 17$ and Il23r. While TGF- $\beta$ and IL-6 drive the initial stages of Th17 cell lineage commitment, IL-21 produced by Th17 cells acts as an autocrine factor that further promotes Th17 cell differentiation by amplifying STAT3 activation through a positive feedback loop. On the other hand, IL-23 plays a critical role in the terminal differentiation and maintenance of Th17 cell lineage through inducing Blimp1 expression in Th17 cells $[11,12]$. The association of Th17 cells with autoimmune disorders in humans has been demonstrated in various diseases including multiple sclerosis, rheumatoid arthritis, inflammatory bowel disease and psoriasis. Indeed, several neutralizing or blocking antibodies targeting Th17/IL-17 pathway have shown clinical efficacy in plaque psoriasis [13-15]. Moreover, development of small molecules targeting STAT3-ROR $\gamma$ t pathway is an active area of new drug development worldwide.

In this study, we aimed to characterize the immunomodulatory effects of ketamine on autoimmune Th17 cell responses. Our findings indicate that ketamine regulates Th17 cell differentiation through the inhibition of autocrine IL-21 production and STAT3 phosphorylation in T cells. As a result, ketamine treatment significantly reduced the pathogenicity of myelin-reactive Th17 cells in a passive EAE model, suggesting a suppressive role in autoimmune Th17 cell responses.

\section{RESULTS}

\section{Ketamine suppresses dendritic cell-mediated Th17 cell differentiation}

Stimulation of naïve $\mathrm{CD}^{+} \mathrm{T}$ cells with dendritic cells in the presence of anti-CD3, LPS and TGF- $\beta$ induces Th17 differentiation [10]. As a first step in examining the effects of ketamine on Th17 cell responses, we determined if ketamine impacts dendritic cell-mediated Th17 cell differentiation in vitro. Compared with vehicle-treated condition, addition of ketamine significantly decreased the frequency of IL-17-expressing $\mathrm{CD}^{+} \mathrm{T}$ cells in a dose dependent manner, while that of Foxp3-expressing cells remained comparable (Figure 1A \& 1B). The amount of IL-17 in the culture supernatant was also remarkably decreased by ketamine treatment in a dose-dependent manner (Figure 1C). Moreover, the levels of $1 l 17 a$,
Il17f, Rorc were all significantly decreased by ketamine treatment compared to vehicle treatment (Figure 1D). The levels of $I l 23 r$, Ccr 6 were also slightly decreased, while that of Rora remained unchanged by ketamine treatment. These results together demonstrate that ketamine inhibited dendritic cell-mediated differentiation of naïve $\mathrm{T}$ cells into Th17 cells.

\section{Ketamine suppresses Th17 cell differentiation in a $T$ cell-intrinsic manner}

Ketamine has been shown to modulate the function of dendritic cells [8]. Therefore, we asked if the observed suppression of Th17 cell differentiation by ketamine was due to the decreased production of Th17-inducing cytokines, such as IL-6, IL-1 $\beta$ and IL-23 [16], from dendritic cells. To this end, we stimulated DCs with LPS in the presence or absence of ketamine for 24 hours before measuring the production of Th17-inducing cytokines. As depicted in Figure 2A, the concentrations of IL-1 $\beta$, IL-6 and IL-23 between vehicle- and ketamine-treated conditions were largely comparable, indicating that ketamine had little role in the production of Th17 cellpromoting cytokines by dendritic cells. Similarly, the production of IL-10 from LPS-stimulated dendritic cells was not affected by ketamine treatment (Figure 2A).

This observation prompted us to ask if ketamine inhibits Th17 cell differentiation in a $\mathrm{T}$ cell-intrinsic manner. To test this hypothesis, we stimulated naïve $\mathrm{CD}^{+} \mathrm{T}$ cells with plate-bound anti-CD3 and anti-CD28 under Th17-skewing condition (IL-6 + TGF- $\beta$ [10]) in the presence of ketamine or vehicle. Notably, we observed a significant reduction in the frequency and number of IL-17-producing $\mathrm{CD}^{+} \mathrm{T}$ cells by ketamine in a dosedependent manner (Figure 2B \& 2C, Supplementary Figure 1A). Consistently, the amount of IL-17 in the supernatant was also remarkably decreased by ketamine treatment (Figure 2D). The frequency of apoptotic cells among $\mathrm{T}$ cells was comparable between vehicleand ketamine-treated groups (Supplementary Figure 1B). Moreover, the reduction of Th17 cell frequency did not result in the increase of $\mathrm{Foxp}^{+}$regulatory $\mathrm{T}$ cells regardless of Th17 cell differentiation condition (Supplementary Figure 1C \& D). Considering the role of TGF- $\beta$ in inducing Foxp $3^{+}$Treg cells [17], this indicates that the inhibition of Th17 cell differentiation by ketamine was not due to the increase of Foxp $3^{+}$Treg cells in this experimental setting. Collectively, these results demonstrate that ketamine induced the inhibition of Th17 cell differentiation in a $\mathrm{T}$ cell-intrinsic manner rather than through the modulation of dendritic cells. 


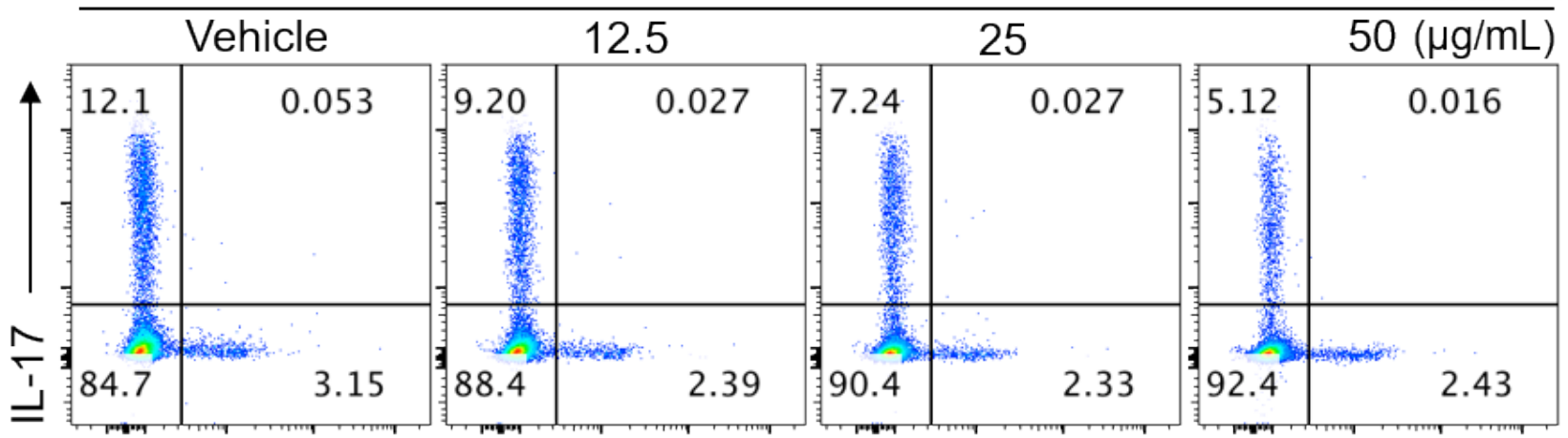

Foxp3

B
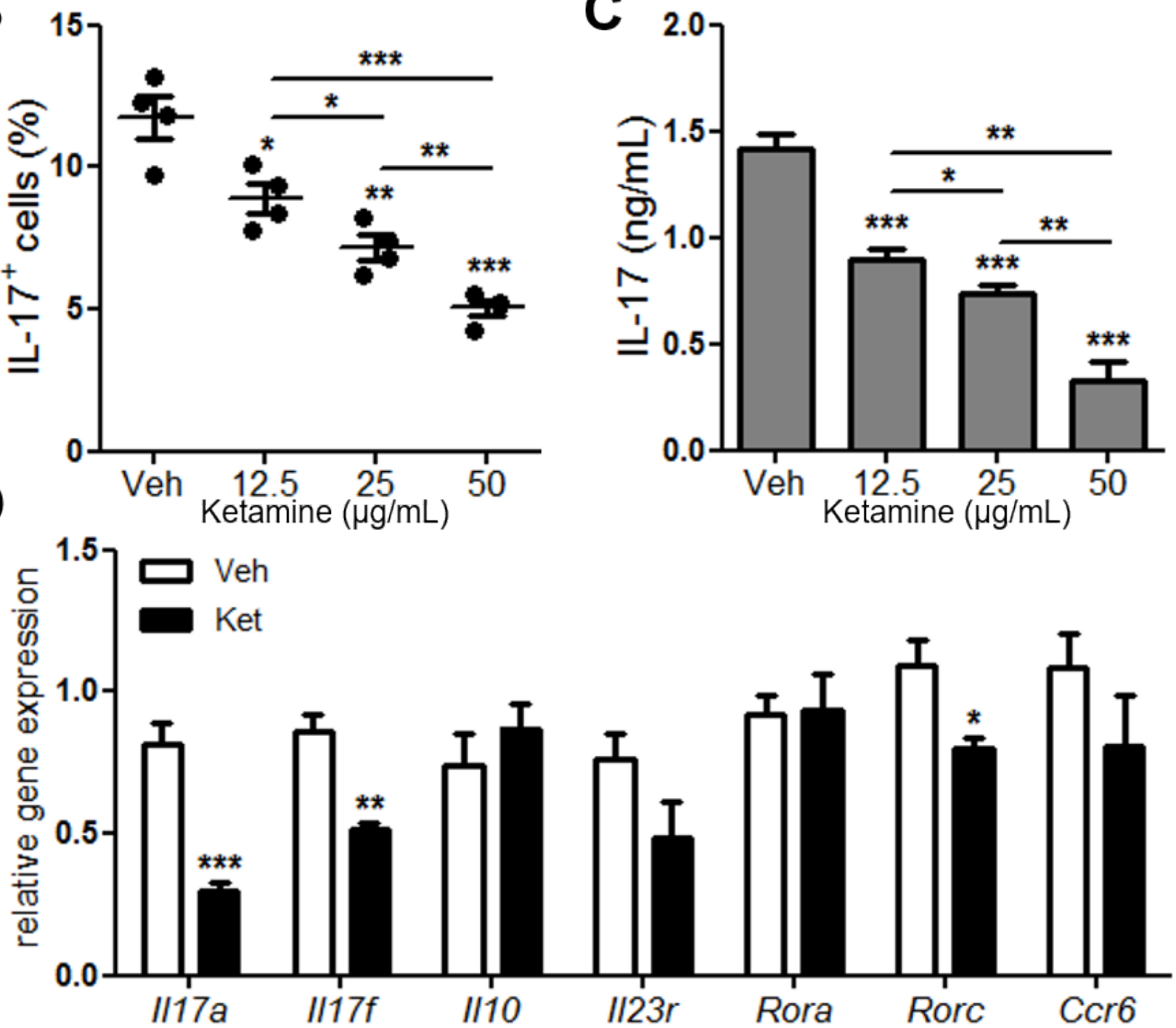

Figure 1: Ketamine inhibits DC-mediated Th17 cell differentiation. Naïve $\mathrm{CD}^{+} \mathrm{T}$ cells and CD11 $\mathrm{c}^{+}$bone marrow-derived dendritic cells were stimulated with soluble anti-CD3 and co-cultured under Th17-skewing condition for 3 days. Detection of IL-17 expression cells was conducted using flow cytometry analysis. A., B. The levels of IL-17 in the supernatant were determined by ELISA. C. The expression levels of indicated transcripts were analyzed by quantitative real-time RT-PCR. D. Data represent three independent experiments. Data shown are mean \pm SEM. ${ }^{*}, p<0.05, * *, p<0.01, * * *, p<0.001$. 
Effects of ketamine on the proliferation of $\mathrm{CD}^{+}$ T cells

To determine the mechanism by which ketamine inhibits Th17 cell differentiation, we asked if ketamine impacts the activation and proliferation of $\mathrm{CD} 4^{+} \mathrm{T}$ cells in response to anti-CD3-mediated stimulation. Naïve $\mathrm{CD}^{+} \mathrm{T}$ cells were labeled with CFSE dye before being stimulated with anti-CD3 and anti-CD28 under Th17-skewing condition. Of note, the frequency of cells that divided more than once was comparable between vehicle-treated

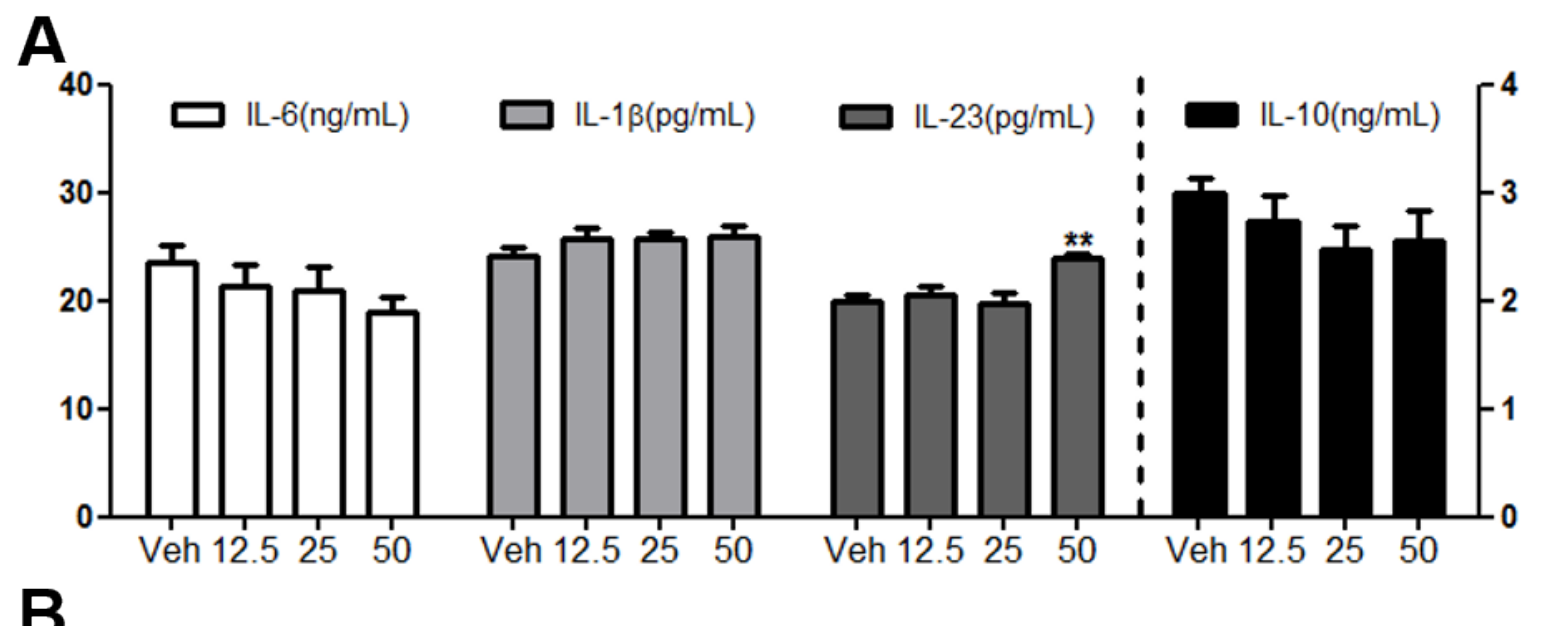

B
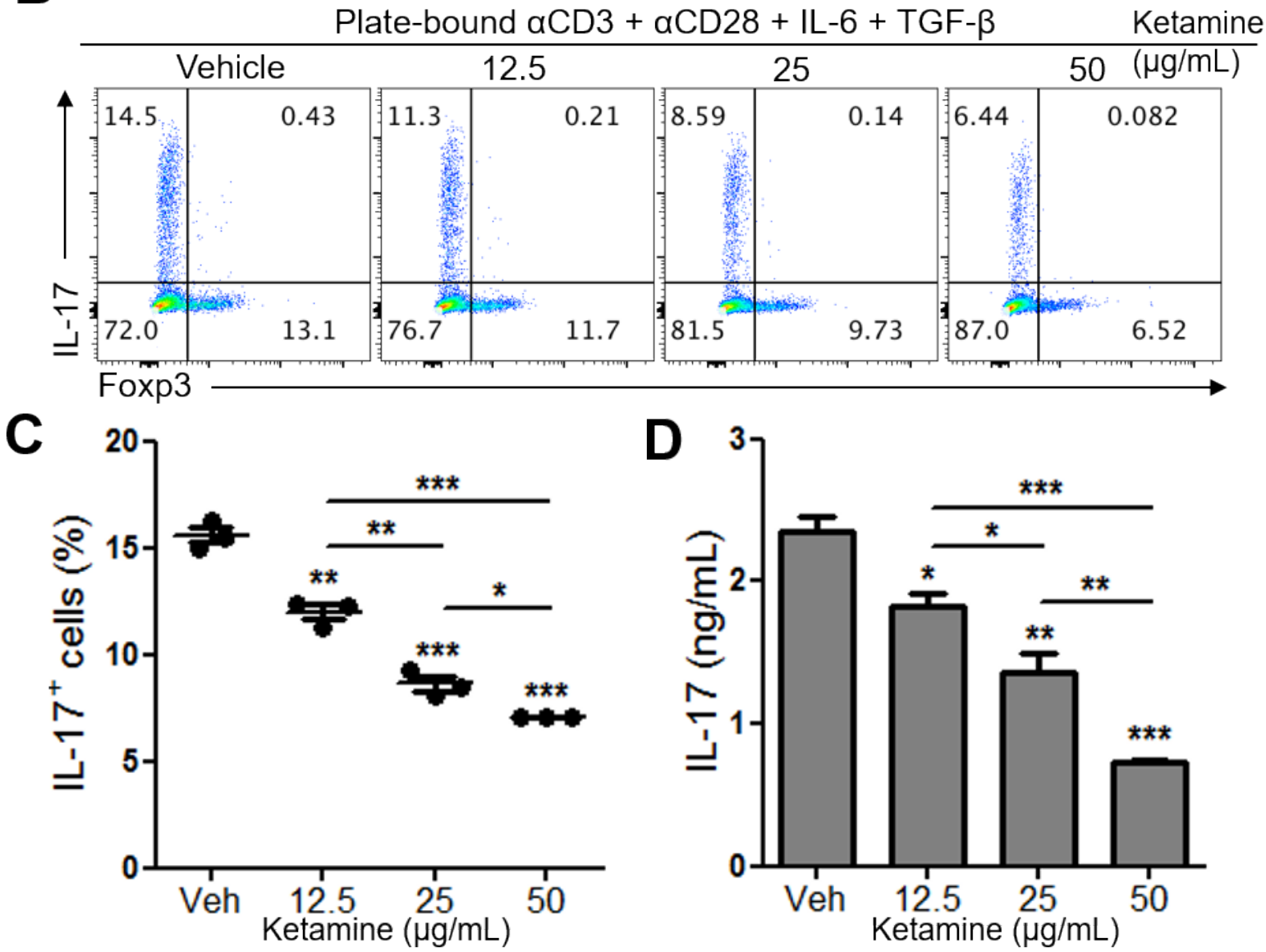

Figure 2: Effect of ketamine on DCs and $\mathrm{CD}^{+} \mathrm{T}$ cells during Th17 cell differentiation. Bone marrow-derived dendritic cells were stimulated with $100 \mathrm{ng} / \mathrm{mL}$ of LPS in the presence of various concentrations of ketamine for 24 hours. The amounts of indicated cytokines in the supernatant were measured by ELISA. A.. FACS-sorted naïve $\mathrm{CD}^{+} \mathrm{T}$ cells were stimulated with plate-bound anti-CD3 and anti-CD28 under Th17-skewing condition for 3 days, and the frequency of IL-17-expressing T cells were analyzed. B., C. IL-17 concentrations of the supernatants were measured by ELISA. D. Data represent at least 3 independent experiments. Data shown are mean \pm SEM. ${ }^{*}, p<0.05, * *, p<0.01,{ }^{* * *}, p<0.001$. 
and ketamine-treated $\mathrm{T}$ cells at the 12.5 , and $25 \mu \mathrm{g} / \mathrm{ml}$ doses (Figure 3A \& 3B). The proliferation of T cells was, however, slightly, but significantly, decreased by ketamine at a higher dose $(50 \mu \mathrm{g} / \mathrm{ml})$.

Ketamine suppresses the phosphorylation of STAT3 and the expression of IL-21 in $\mathrm{CD4}^{+} \mathrm{T}$ cells upon IL-6 stimulation

Stimulation of naïve $\mathrm{CD}^{+} \mathrm{T}$ cells with IL-6 and TGF- $\beta$ efficiently induces the expression of ROR $\gamma \mathrm{t}$ and IL-17, but not IL-22, by T cells [10] (Figure 4A). On the other hand, stimulation of T cells with IL-1 $\beta$, IL-6 plus IL-23 in the absence of exogenous TGF- $\beta$ is also known to trigger the differentiation of Th17 cells that produce IL-22 $[18,19]$. We sought to determine whether ketamine also inhibits the differentiation of Th17 cells induced by IL$1 \beta$, IL-6 plus IL-23, and found that addition of ketamine significantly suppressed the production of IL-17, as well as IL-22 from T cells in a dose dependent manner (Figure 4B). The magnitude of IL-17 suppression by ketamine appeared to be more significant in the IL-6, IL-23 and IL$1 \beta$ stimulation condition (Figure 4A \& 4B). The level of transcription factor ROR $\gamma \mathrm{t}$ in $\mathrm{T}$ cells was also significantly decreased by ketamine treatment (Figure 4A \& 4B).

Since IL-6 was the only common cytokine in the two different Th17 cell differentiation conditions inhibited by ketamine, we reasoned that ketamine suppresses Th17 cell differentiation probably by inhibiting IL-6 signaling pathway. IL-6 signals through STAT3 to induce autocrine IL-21 secretion in $\mathrm{CD}^{+}{ }^{+}$cells during Th17 cell differentiation [20,21]. Of interest, ketamine significantly decreased the mRNA transcription and protein production of IL-21 from T cells stimulated with IL-6 in the presence of anti-CD3 (Figure 5A). To further explore the molecular mechanism, we determined the involvement of STAT3 and found that the level of phosphorylated STAT3 in T cells induced by IL- 6 was significantly diminished by ketamine treatment (Figure 5B). The mean fluorescence intensity of phosphorylated STAT3 was dramatically decreased by ketamine compared to vehicle-treated cells with $p$ value of 0.0025 (Figure 5B). Collectively, these data demonstrate that ketamine suppresses Th17 cell differentiation program by inhibiting the phosphorylation of STAT3 upon IL-6 stimulation and subsequent expression of IL-21 in T cells.

\section{Ketamine suppresses autoimmune Th17 cells}

Since Th17 cells are known to mediate tissue inflammation during autoimmune diseases, we next asked if ketamine also impacts autoimmune Th17 cell responses. Immunization with myelin oligodendrocyte glycoprotein $\left(\mathrm{MOG}_{35-55}\right)$ peptide induces the generation of autoreactive $\mathrm{T}$ cells that can trigger the onset of experimental autoimmune encephalomyelitis (EAE) in mice [22]. We immunized C57BL/6 mice with MOG in CFA, and isolated lymphoid cells from the draining lymph nodes, and stimulated them with MOG in the presence of IL-23, which triggers the expansion of MOG-reactive autoimmune Th17 cells [23]. Addition of ketamine remarkably decreased the frequency of IL-17-producing cells among $\mathrm{CD}^{+} \mathrm{T}$ cells (Figure $6 \mathrm{~A} \& 6 \mathrm{~B}$ ), indicating the inhibitory effect of ketamine on the expansion of autoimmune Th17 cells. By contrast, little change in the frequency of Foxp $3^{+} \mathrm{T}$ cells by ketamine treatment was observed in this experimental setting (Supplementary Figure 2).

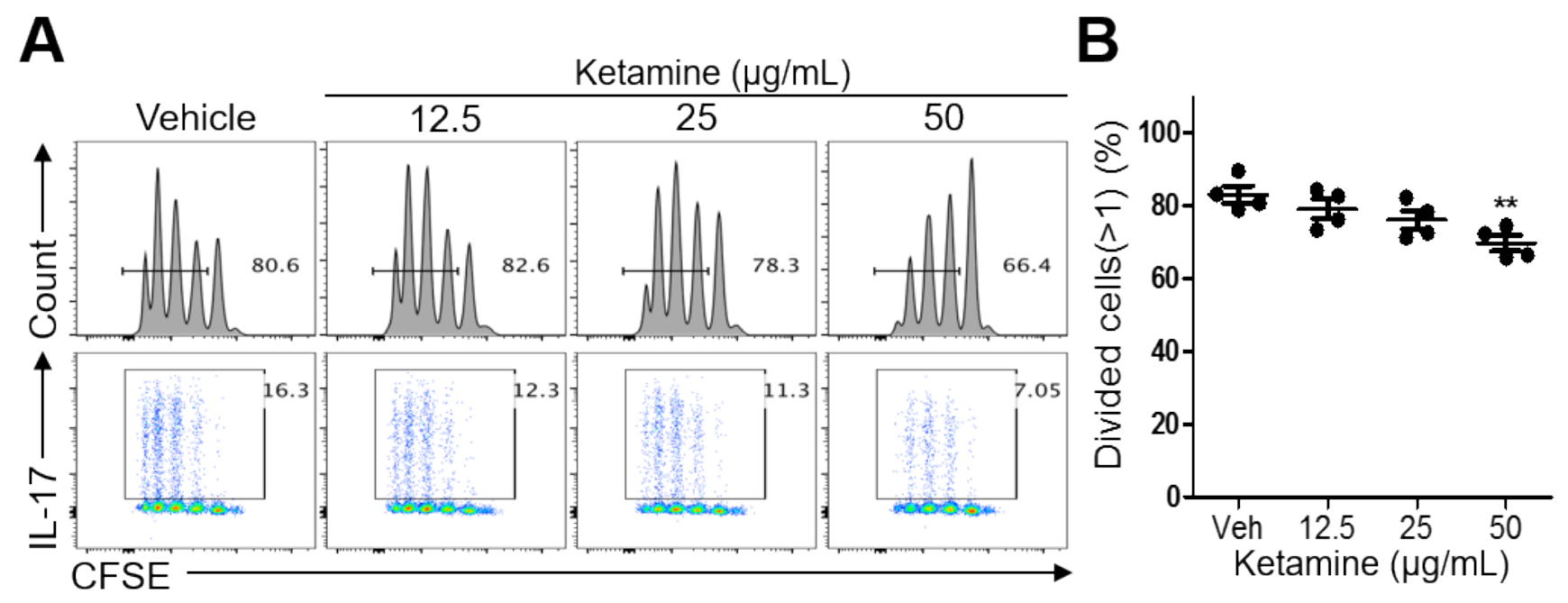

Figure 3: Effect of ketamine on the proliferation of T cells during Th17 cell differentiation. Naïve CD4 ${ }^{+} \mathrm{T}$ cells were labeled with CFSE before being stimulated with plate-bound anti-CD3 and anti-CD28 under Th17-skewing condition for 3 days. The dilution of CFSE and the frequency of IL-17-expressing cells were analyzed by flow cytometry. A. The proportion of cells divided more than once was measured. B. Data represent two independent experiments. Data shown are mean \pm SEM. *, $p<0.05, * *, p<0.01, * * *, p<0.001$. 
When these cells were adoptively transferred into $\mathrm{Tcrb}^{-/}$recipient mice, the recipients of ketamine-treated $\mathrm{T}$ cells exhibited significantly less severe EAE (max clinical score: $2.83 \pm 0.44$ vs. $0.25 \pm 0.25, p=0.0028$ ) associated with less severe loss of body weight in comparison with the recipients of vehicle-treated $\mathrm{T}$ cells (Figure 6C). Analysis of the $\mathrm{CD}^{+} \mathrm{T}$ cells isolated from brain and spinal cord showed a significant decrease in IFN- $\gamma^{+} \mathrm{IL}-17^{+}$as well as $\mathrm{GM}-\mathrm{CSF}^{+} \mathrm{IL}-17^{+} \mathrm{T}$ cells in the recipients of ketamine- treated T cells (Figure 6D \& 6E). These results indicate that the differentiation of MOG-reactive IL- $17^{+} \mathrm{T}$ cells into pathogenic IFN- $\gamma^{+} \mathrm{IL}-17^{+} \mathrm{T}$ cells in vivo was significantly attenuated by ketamine treatment, although the frequency of total IL- $17^{+} \mathrm{T}$ cells remained unaffected. Collectively, these results demonstrate that ketamine inhibited the expansion and/or reactivation of pathogenic autoimmune Th17 cell responses.
A

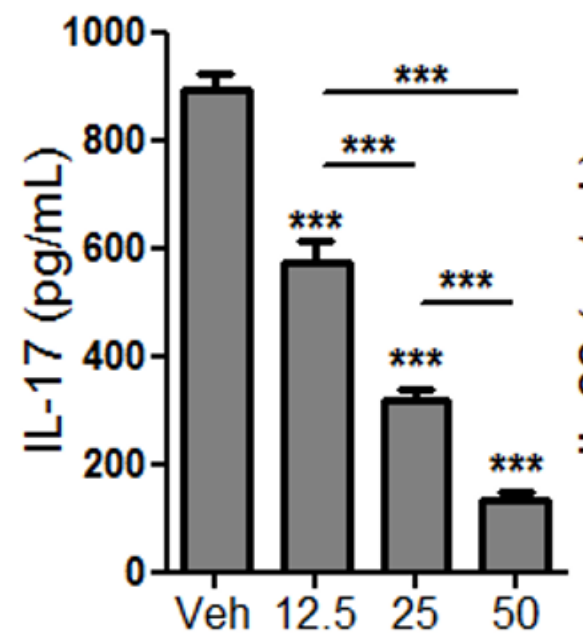

B

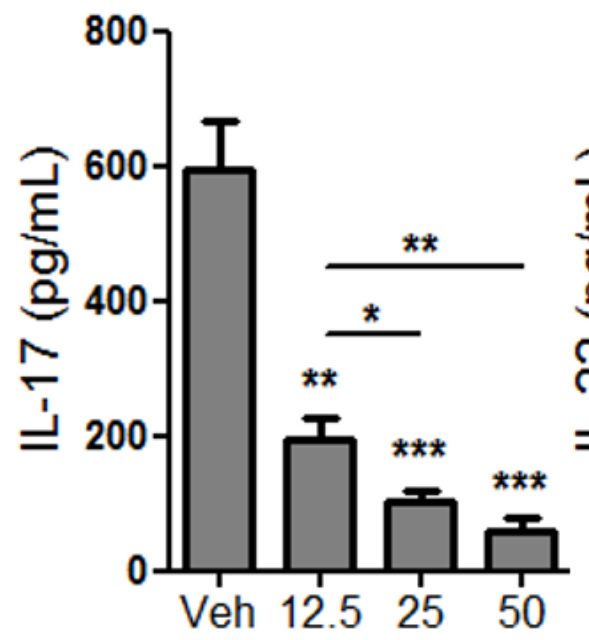

IL-6 + TGF- $\beta$
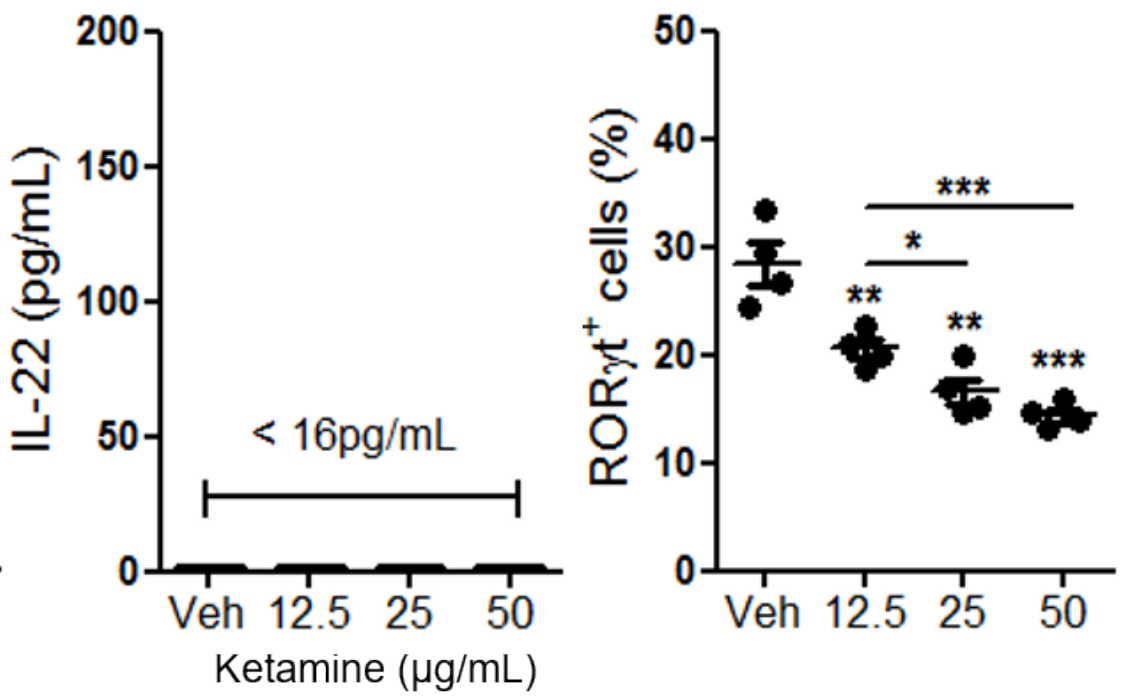
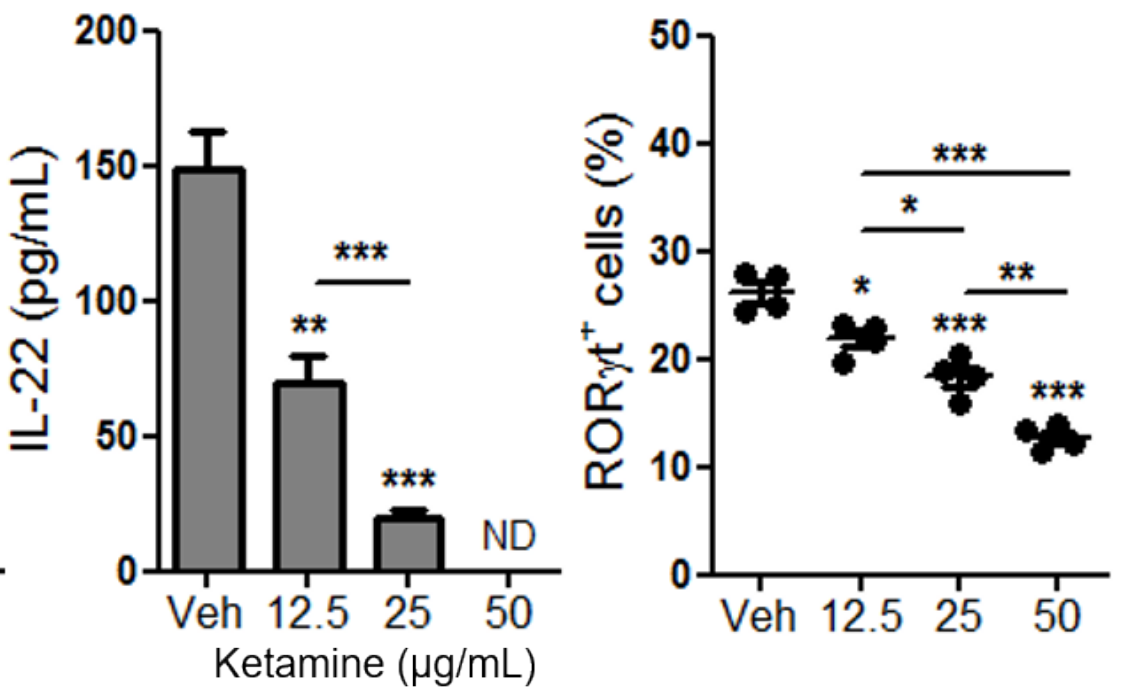

Figure 4: Ketamine inhibits Th17 cell differentiation induced by IL-6, IL-1 $\beta$ and IL-23 in the absence of exogenous TGF- $\beta$. Naïve $\mathrm{CD}^{+}{ }^{+} \mathrm{T}$ cells were stimulated with plate-bound anti-CD3 and anti-CD28 in the presence of IL-6 plus TGF- $\beta$. A. or IL-1 $\beta$ plus IL-6 plus IL-23 B. for 3 days. The levels of IL-17 and IL-22 in the supernatant as well as the frequency of ROR $\gamma$ t-expressing T cells were analyzed by ELISA and flow cytometry, respectively. ND, Not detectable. Data represent two independent experiments. Data shown are mean \pm SEM. ${ }^{*}, p<0.05, * *, p<0.01, * * *, p<0.001$. 


\section{DISCUSSION}

Considering the critical contribution of immune cells to wound healing and host defense [24], it seems reasonable to surmise that the immune-modulatory functions of anesthetic agents affect the postoperative recovery in patients [25]. In this regard, ketamine is known to suppress Th1 cell-mediated immune responses and to inhibit the maturation and activation of dendritic cells [8]. Ketamine has also been shown to decrease IL-6 and TNF- $\alpha$ in human peripheral blood mononuclear cells (PBMCs) [26]. Accumulating evidence demonstrates a crucial pathogenic role of Th17 cells in mediating autoimmune diseases in humans $[27,28]$. However, no studies to date have addressed if ketamine plays any role on Th17 cell responses and Th17 cell-mediated immune diseases.

In the present study, we unveil that ketamine negatively regulates the differentiation and reactivation of Th17 cells. Although it has been reported that ketamine inhibits Th1 differentiation through suppressing IL-12p40 production by dendritic cells [8], ketamine had little role in the production of Th17-promoting cytokines including IL-6, IL-23 and IL-1 $\beta$ by DCs, strongly suggesting that ketamine directly impacts $\mathrm{T}$ cells. Indeed, we observed

\section{A}
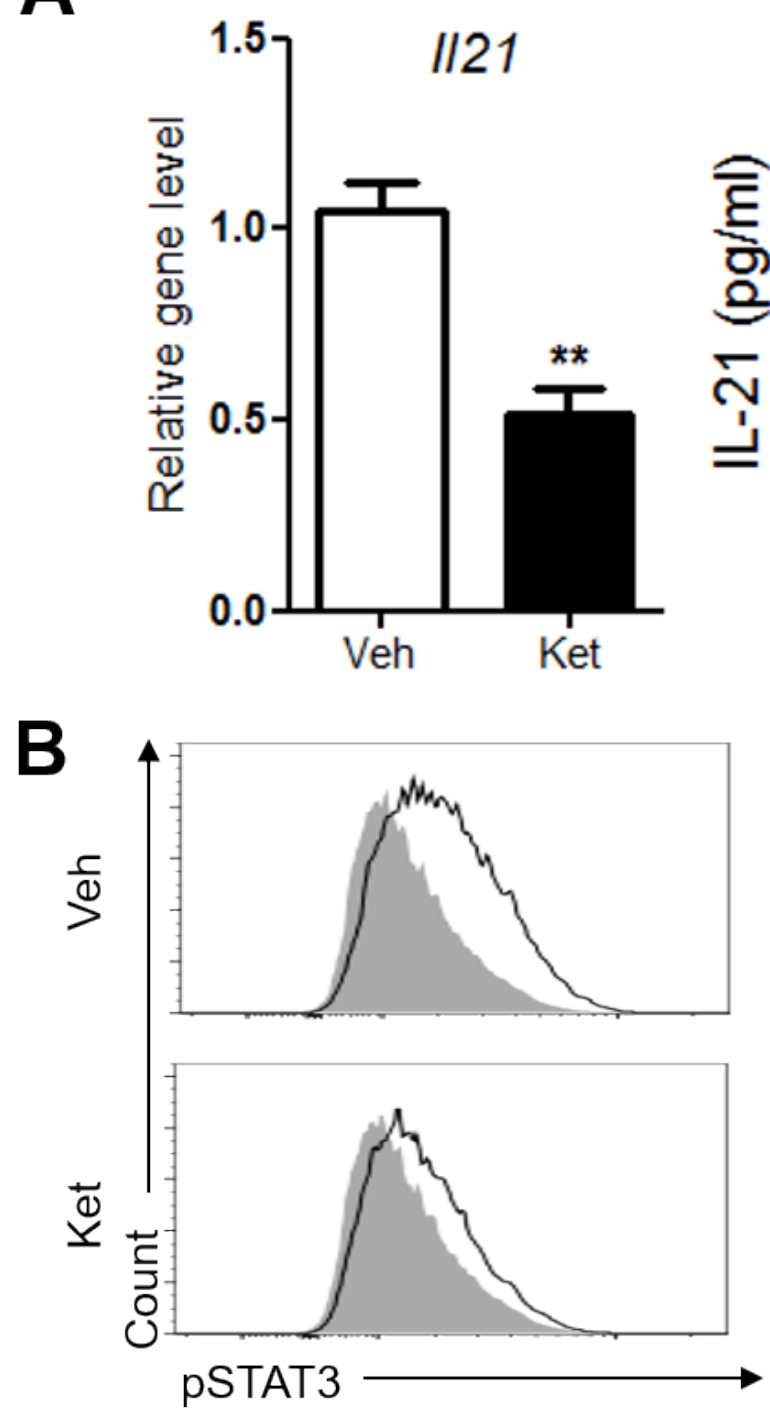
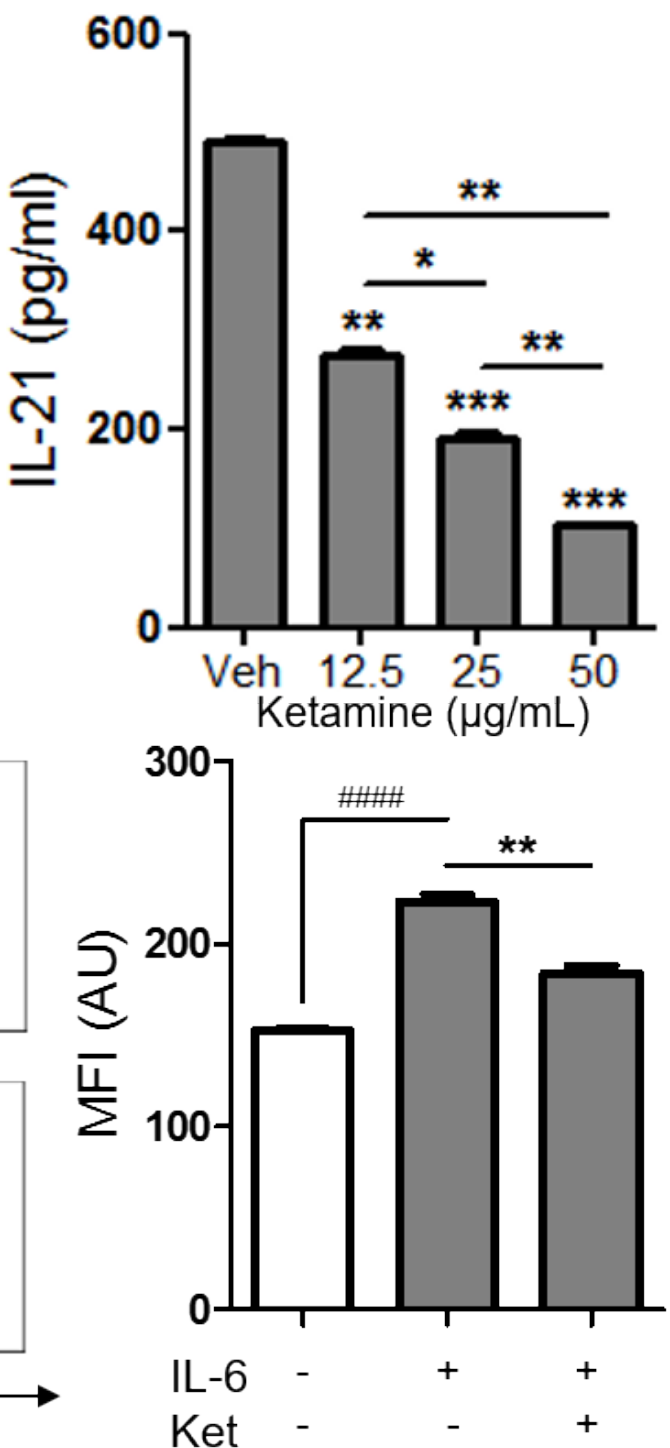

Figure 5: Ketamine negatively regulates the expression of IL-21 and the phosphorylation of STAT3 during Th17 cell differentiation. Naïve $\mathrm{CD}^{+}{ }^{\mathrm{T}}$ cells were stimulated with plate-bound anti-CD3 and anti-CD28 under Th17-skewing condition for 48 hours in the presence or absence of ketamine. The level of $I l 21$ transcript as well as IL-21 in the supernatant was determined. A. The levels of phosphorylated STAT3 in $\mathrm{CD}^{+} \mathrm{T}$ cells stimulated under plate-bound anti-CD3 and anti-CD28 plus IL- 6 conditions were measured by flow cytometry. B. Shaded, IL-6 unstimulated negative control; closed line, vehicle or ketamine treated; NC. Data represent two independent experiments. Data shown are mean \pm SEM. * $p<0.05,{ }^{* *}, p<0.01, * * *, p<0.001$, \#\#\#, $p<0.0001$. 
that ketamine treatment significantly inhibited Th17 cell differentiation in DC-free Th17-skewing conditions. In the CFSE-dilution assay, we observed little effect of ketamine on the proliferation of naïve $\mathrm{CD}^{+} \mathrm{T}$ cells in response to anti-CD3. Instead, ketamine suppressed the differentiation of naïve T cells into Th17 cells by inhibiting IL-6-mediated STAT3 phosphorylation, leading to a significant decrease in the expression of IL-21 and ROR $\gamma \mathrm{t}$ in T cells. Upon IL-6 stimulation, phosphorylated STAT3 in T cells induce multiple Th17-related genes, including Il17, Il21, Rorc, Irf4 and Ahr [29]. Since STAT3 is a crucial factor for IL21 induction, as well as one of the downstream mediators of the IL-21 signaling pathway, it is unclear whether the decrease in IL-21 production from $\mathrm{T}$ cells by ketamine was the result of, or the cause of the reduced STAT3 phosphorylation in T cells. It is likely that diminished phosphorylation of STAT3 resulted in decreased expression of IL-21 in T cells, which further prolonged the decreased STAT3 phosphorylation. Further studies will be needed to determine the molecular mechanism by which ketamine suppresses STAT3 phosphorylation in T cells.

In addition to its inhibitory role in early Th17 cell differentiation, ketamine was also found to suppress the reactivation of MOG-specific Th17 cells upon IL-23 stimulation. Upon transfer into lymphopenic recipient mice, MOG-specific Th17 cells expanded in the presence of ketamine were less pathogenic in inducing EAE in the recipients in comparison to those expanded in the presence of vehicle. Analysis of $\mathrm{CD}^{+} \mathrm{T}$ cells in the CNS revealed a significant reduction in the frequencies

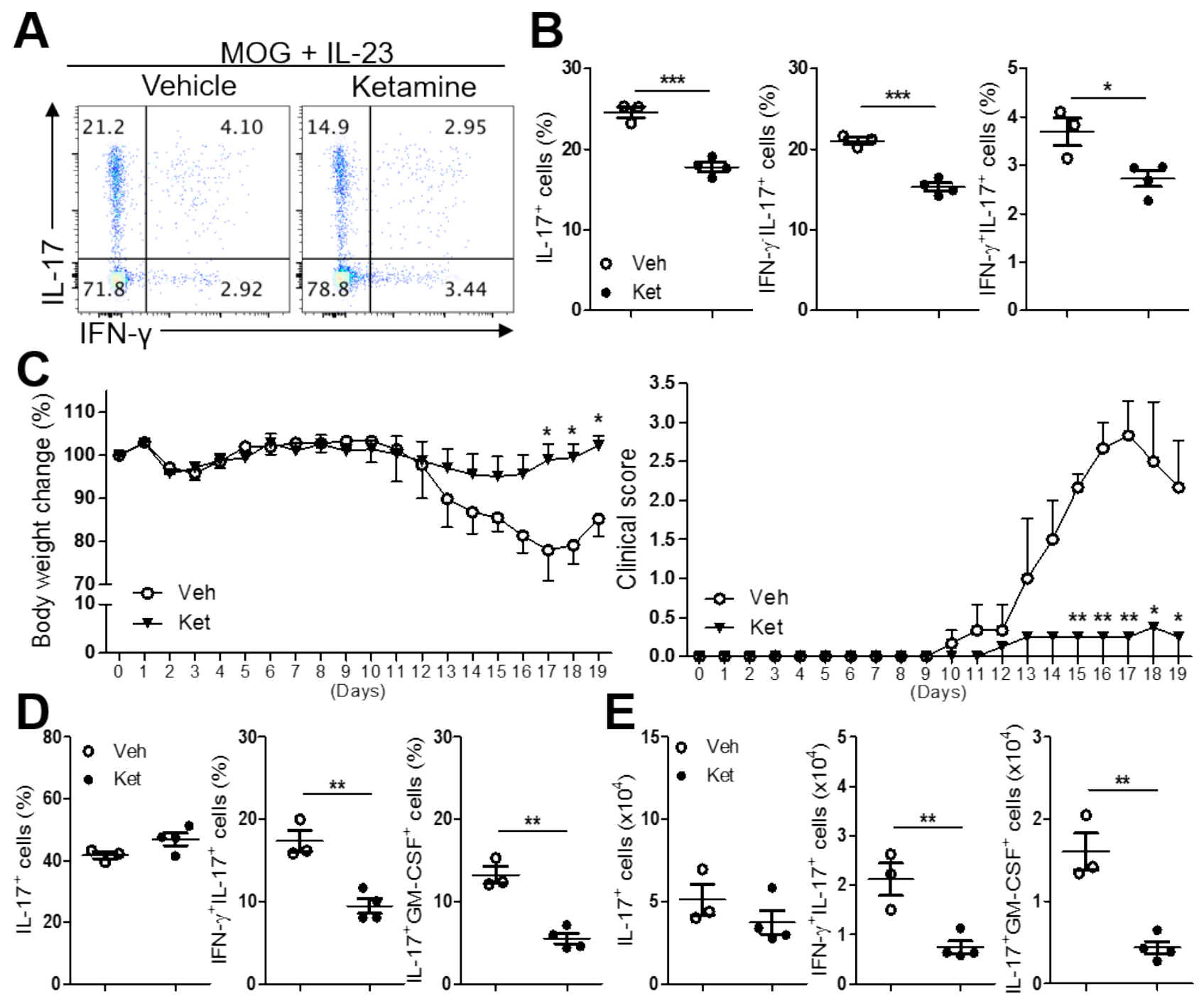

Figure 6: Ketamine inhibits the reactivation of MOG-reactive Th17 cells. Lymphoid cells from the MOG-immunized mice were re-stimulated with MOG peptide plus IL-23 in the presence of ketamine or vehicle for 5 days before CD4+ T cells were sorted by MACS. The expression of IL-17 and IFN- $\gamma$ was measured. A., B. The sorted CD4 ${ }^{+}$T cells were i.v. transferred into TCR $\beta$-deficient mice and the recipient mice were s.c. injected with MOG in CFA. Body weight and clinical disease score were daily monitored $\mathbf{C}$., and the frequencies and absolute numbers of the indicated population among $\mathrm{CD}^{+} \mathrm{T}$ cells in the CNS of the recipients were determined $\mathbf{D}$. \& $\mathbf{E}$. Data represent two independent experiments. Data shown are mean \pm SEM. ${ }^{*}, p<0.05, * *, p<0.01, * * *, p<0.001$. 
of IFN- $\gamma^{+} \mathrm{IL}-17^{+}$cells and GM-CSF ${ }^{+} \mathrm{IL}-17^{+}$cells in the former group, both of which play a critical role in Th17mediated CNS inflammation. These results strongly suggest that ketamine significantly impairs the terminal differentiation of autoimmune Th17 cells into pathogenic IFN- $\gamma^{+} \mathrm{IL}-17^{+}$cells and GM-CSF ${ }^{+} \mathrm{IL}_{-1} 7^{+}$cells. Since IL-23 also signals through STAT3 activation [30], it is possible to surmise that ketamine also suppresses IL-23mediated phosphorylation of STAT3 in Th17 cells during reactivation. IL-23 induces the expression of Blimp1 to stabilize the Th17 cell lineage program [31]. Thus, it is also possible that ketamine inhibits the induction of Blimp1 expression upon IL-23 stimulation in Th17 cells. The exact mechanism by which ketamine suppresses the reactivation of Th17 cells is, however, unclear at this stage.

In summary, the present study unveils a strong inhibitory effect of ketamine on Th17 cell responses at two different stages, differentiation and reactivation. The strength of this study is the possibility of clinical applicability. Besides the treatment of chronic pain, ketamine or its derivatives can be further considered as a novel therapeutic approach for Th17 cell-mediated diseases in humans such as psoriasis [32] and rheumatoid arthritis [33]; however, additional mechanistic and translational studies will be needed before applying our findings into clinical settings in humans.

\section{MATERIALS AND METHODS}

\section{Ethics approval}

All mouse experiments were performed as approved by Seoul National University Institutional Animal Care and Use Committee (IACUC, Seoul National University approved protocol \#SNU- 160422-3-1).

\section{Mice}

C57BL/6 mice within the ages of 6-10 weeks were purchased from Orient Bio (Gyeonggi, Republic of Korea). $\mathrm{Tcrb}^{-/}$mice were purchased from Jackson Laboratories (Maine, USA). Mice were maintained under semi-specific-pathogen-free animal facility in sterile, individually ventilated cages at the Seoul National University with free access to sterile water. $\mathrm{CO}_{2}$ inhalation was used for euthanasia.

\section{In vitro $\mathrm{T}$ cell differentiation}

$\mathrm{CD}^{+} \mathrm{T}$ cells were isolated from C57BL/6 mice were enriched by CD4 microbeads (Miltenyi Biotec), followed by sorting $\mathrm{CD} 4^{+} \mathrm{CD} 25^{-} \mathrm{CD} 62 \mathrm{~L}^{\text {hi }} \mathrm{CD} 44^{\text {lo }}$ cells using the
FACSARIA III (BD Biosciences). For DC:T co-culture experiments, sorted naïve $\mathrm{CD}^{+} \mathrm{T}$ cells $\left(1.0 \times 10^{5}\right.$ cells/ well) were co-cultured with $\mathrm{CD} 11 \mathrm{c}^{+}$bone marrow-derived DCs $\left(1.0 \times 10^{4}\right.$ cells/well $)$ in the presence of soluble anti-CD3 $(0.3 \mu \mathrm{g} / \mathrm{mL})$, LPS (100 ng/mL), and TGF- $\beta$ ( $5 \mathrm{ng} / \mathrm{mL}$ ). For plate-bound Th17 cell differentiation experiments, sorted naïve $\mathrm{CD}^{+}{ }^{+} \mathrm{T}$ cells $\left(1.0 \times 10^{5} /\right.$ well $)$ were stimulated with plate-bound anti-CD3 and anti-CD28 in the presence of IL- $6(20 \mathrm{ng} / \mathrm{mL})$, and TGF- $\beta(5 \mathrm{ng} / \mathrm{mL})$ or IL-6 (40 ng/mL), IL-1 $\beta$ (10 ng/mL), and IL-23 (50 ng/ $\mathrm{mL})$. The concentrations of treated ketamine (Ketamine hydrochloride, Yuhan Co., Korea) were 12.5, 25, 50 $\mu \mathrm{g} / \mathrm{mL}$ and sterile water was used as vehicle.

\section{Flow cytometry for cytokine analysis}

Cells cultured or obtained from mice were incubated for 4 hours with Phorbol 12-myristate 13-acetate (PMA) (100 ng/mL, Sigma, St Louis, MO, USA) and ionomycin ( $1 \mu \mathrm{M}$, Sigma, St Louis, MO, USA) in the presence of Brefeldin A and Monensin (eBioscience, San Diego, CA, USA). The stimulated T cells were treated in Fix/ Permeabilization buffer. PE- or APC-conjugated antiIL-17A (Biolegend), PerCP/Cy5.5-conjugated antiIFN- $\gamma$ (Biolegend), PE-conjugated anti-ROR $\gamma$ t, eFlour 450-conjugated anti-Foxp3 (eBioscience), Alexa Flour 488-conjugated anti-STAT3 phospho(Tyr705) (Biolegend) were used for intracellular staining. To analyze CNSinfiltrating immune cells, lymphoid cells from CNS were stained with PE/Cy7-conjugated anti-CD4 (eBioscience), PE-conjugated anti-GM-CSF (Biolegend), PerCP/Cy5.5conjugated anti-IFN- $\gamma$ (Biolegend), and Alexa Flour 488-conjugated anti-IL-17A (Biolegend). Samples were analyzed using the FACSVerse flow cytometer (BD Bioscience, San Jose, CA) and data were analyzed through the FlowJo software (TreeStar, Ashland, OR) [34].

\section{Cytokine ELISA}

The amounts of IL-1 $\beta$, IL-6, IL-21, IL-23, IL-17 and IL-22 cytokines in the culture supernatant were measured using an ELISA kit (Biolegend and eBioscience). All assays were performed according to the manufacturer's protocol. For IL-17 detection, samples were obtained after 3-4 days of T cell differentiation. For IL-21 detection by IL- 6 stimulation, cells were stimulated by IL- 6 for 48 hours and re-stimulated by anti-CD3 coated condition after normalization to $1.0 \times 10^{5}$ cells/well in 96-well culture plate. For IL-1 $\beta$, IL-6, IL-10, IL-23 detection from dendritic cells, cultured BMDCs were purified by CD $11 \mathrm{c}^{+}$ micro-bead before being treated with indicated conditions for 24 hours. 


\section{Quantitative real-time PCR}

Total RNA was obtained from in vitro cultured $\mathrm{CD}^{+}$ T cells with TRIzol (Invitrogen). Complementary DNA was synthesized with amfiRivert reverse transcriptase (GenDEPOT) and the levels of indicated mRNA transcript were quantified by iTaq Universal SYBR Green Supermix (Bio-Rad Laboratories) with ABI-PRISM 7900 detection system (Applied Biosystems). All the data were normalized to the expression of Gapdh. The primer pair for Gapdh was: forward, 5'-GAGAACTTTGGCATTGTGG-3', reverse, 5'-ATGCAGGGATGATGTTCTG-3'. The primer pairs of $I l 17 a, I l 17 f$, Ill0, Il21, Il23r, Rora, Rorc and Ccr6 were previously described[35]. The concentration of treated ketamine (Ketamine hydrochloride, Yuhan Co., Korea) was $50 \mu \mathrm{g} / \mathrm{mL}$ and sterile water was used as vehicle.

\section{Ex vivo re-stimulation of MOG-reactive $\mathrm{T}$ cells and in vivo $\mathrm{CD}^{+} \mathrm{T}$ cell transfer $\mathrm{EAE}$}

C57BL/6 mice were subcutaneously immunized with $100 \mu \mathrm{lmix}$ of $300 \mu \mathrm{g}$ of $\mathrm{MOG}_{35-55}$ and $100 \mu \mathrm{g}$ of CFA (Sigma Aldrich) containing killed M. tuberculosis $(5 \mathrm{mg} / \mathrm{ml})$ for 7-8 days [35]. After immunization period, lymphoid cells from the inguinal lymph nodes were stimulated with $\mathrm{MOG}_{35-55}(20 \mu \mathrm{g} / \mathrm{mL})$ in the presence of IL-23 $(20 \mathrm{ng} / \mathrm{mL})$, anti-IFN- $\gamma(X M G 1.2,10 \mu \mathrm{g} / \mathrm{mL})$ plus vehicle (sterile water) or ketamine $(50 \mu \mathrm{g} / \mathrm{mL})$ for 5 days. The expression of IL-17 and IFN- $\gamma$ was analyzed by flow cytometry. For in vivo $\mathrm{CD}^{+} \mathrm{T}$ cell transfer EAE study, the re-stimulated $\mathrm{CD}^{+} \mathrm{T}$ cells were purified intravenously transferred to $T c r b^{-/}$recipient mice $\left(0.6-2 \times 10^{5}\right.$ cells) (day $0)$. On day 1 , the recipients were immunized with $\mathrm{MOG}_{35}$. ${ }_{55}$ in CFA and were injected with pertussis toxin on day 2. Body weight and clinical score were monitored daily.

\section{Statistics}

Data were analyzed by using the GraphPad Prism 5 (GraphPad Software). The Student's unpaired two-tailed t-test with $95 \%$ of confidence intervals was applied for statistical analyses. Data shown are presented in mean \pm SEM and $\mathrm{p}$ values were calculated with $t$-test.

\section{Author contributions}

JEL, JML, YC, YTJ designed the studies; JML, YTJ provided materials; JEL, YJP, BSK conducted the experiments; JEL, JML, YC analyzed the data; JEL, JML, YC, YTJ wrote the manuscript.

\section{ACKNOWLEDGMENTS}

We thank entire Chung lab members for advice and comments in this project, and especially thank Ms. Da-Sol Kuen for proof-reading the manuscript.

\section{CONFLICTS OF INTEREST}

None declared.

\section{FUNDING}

This work is supported by research grants 2014R1A2A1A11054364 (YC) from the National Research Foundation of Korea (NRF).

\section{REFERENCES}

1. Sekandarzad MW, van Zundert AA, Lirk PB, Doornebal CW, Hollmann MW. Perioperative Anesthesia Care and Tumor Progression. Anesth Analg. 2017; 124:1697-708

2. Polak PE, Dull RO, Kalinin S, Sharp AJ, Ripper R, Weinberg G, Schwartz DE, Rubinstein I, Feinstein DL. Sevoflurane reduces clinical disease in a mouse model of multiple sclerosis. J Neuroinflammation. 2012; 9:272.

3. Ji FH, Wang YL, Yang JP. Effects of propofol anesthesia and sevoflurane anesthesia on the differentiation of human T-helper cells during surgery. Chin Med J (Engl). 2011; 124:525-29.

4. Jeon YT, Na H, Ryu H, Chung Y. Modulation of Dendritic Cell Activation and Subsequent Th1 Cell Polarization by Lidocaine. PLoS One. 2015; 10:e0139845.

5. Morgan CJ, Curran HV, and Independent Scientific Committee on Drugs. Ketamine use: a review. Addiction. 2012; 107:27-38.

6. Iadarola ND, Niciu MJ, Richards EM, Vande Voort JL, Ballard ED, Lundin NB, Nugent AC, Machado-Vieira R, Zarate CA Jr. Ketamine and other N-methyl-D-aspartate receptor antagonists in the treatment of depression: a perspective review. Ther Adv Chronic Dis. 2015; 6:97-114.

7. Sleigh J, Harvey M, Voss L, Denny B. Ketamine - More mechanisms of action than just NMDA blockade. Trends in Anaesthesia and Critical Care. 2014; 4:76-81.

8. Ohta N, Ohashi Y, Fujino Y. Ketamine inhibits maturation of bone marrow-derived dendritic cells and priming of the Th1-type immune response. Anesth Analg. 2009; 109:793800.

9. Kim BS, Park YJ, Chung Y. Targeting IL-17 in autoimmunity and inflammation. Arch Pharm Res. 2016; 39:1537-47.

10. Veldhoen M, Hocking RJ, Atkins CJ, Locksley RM, Stockinger B. TGFbeta in the context of an inflammatory cytokine milieu supports de novo differentiation of IL-17- 
producing T cells. Immunity. 2006; 24:179-89.

11. McGeachy MJ, Chen Y, Tato CM, Laurence A, JoyceShaikh B, Blumenschein WM, McClanahan TK, O'Shea JJ, Cua DJ. The interleukin 23 receptor is essential for the terminal differentiation of interleukin 17-producing effector T helper cells in vivo. Nat Immunol. 2009; 10:314-24.

12. Guo W, Yu D, Wang X, Luo C, Chen Y, Lei W, Wang C, Ge Y, Xue W, Tian Q, Gao X, Yao W. Anti-inflammatory effects of interleukin-23 receptor cytokine-binding homology region rebalance $\mathrm{T}$ cell distribution in rodent collagen-induced arthritis. Oncotarget. 2016; 7:31800-13. https://doi.org/10.18632/oncotarget.9309

13. Hueber W, Patel DD, Dryja T, Wright AM, Koroleva I, Bruin G, Antoni C, Draelos Z, Gold MH, Durez P, Tak PP, Gomez-Reino JJ, Foster CS, et al. Effects of AIN457, a Fully Human Antibody to Interleukin-17A, on Psoriasis, Rheumatoid Arthritis, and Uveitis. Sci Transl Med. 2010; 2:52ra72.

14. Leonardi C, Matheson R, Zachariae C, Cameron G, Li L, Edson-Heredia E, Braun D, Banerjee S. Anti-interleukin-17 monoclonal antibody ixekizumab in chronic plaque psoriasis. N Engl J Med. 2012; 366:1190-99.

15. Gordon KB, Blauvelt A, Papp KA, Langley RG, Luger T, Ohtsuki M, Reich K, Amato D, Ball SG, Braun DK, Cameron GS, Erickson J, Konrad RJ, et al, and UNCOVER-1 Study Group, and UNCOVER-2 Study Group, and UNCOVER-3 Study Group. Phase 3 Trials of Ixekizumab in Moderate-to-Severe Plaque Psoriasis. N Engl J Med. 2016; 375:345-56.

16. Mills KH. Induction, function and regulation of IL-17producing T cells. Eur J Immunol. 2008; 38:2636-49.

17. Lutz MB. Induction of CD4(+) Regulatory and Polarized Effector/helper T Cells by Dendritic Cells. Immune Netw. 2016; 16:13-25.

18. Ghoreschi K, Laurence A, Yang XP, Tato CM, McGeachy MJ, Konkel JE, Ramos HL, Wei L, Davidson TS, Bouladoux N, Grainger JR, Chen Q, Kanno Y, et al. Generation of pathogenic $\mathrm{T}(\mathrm{H}) 17$ cells in the absence of TGF- $\beta$ signalling. Nature. 2010; 467:967-71.

19. Chung Y, Chang SH, Martinez GJ, Yang XO, Nurieva R, Kang HS, Ma L, Watowich SS, Jetten AM, Tian Q, Dong C. Critical regulation of early Th17 cell differentiation by interleukin-1 signaling. Immunity. 2009; 30:576-87.

20. Nurieva R, Yang XO, Martinez G, Zhang Y, Panopoulos AD, Ma L, Schluns K, Tian Q, Watowich SS, Jetten AM, Dong C. Essential autocrine regulation by IL-21 in the generation of inflammatory T cells. Nature. 2007; 448:480 83.

21. Korn T, Bettelli E, Gao W, Awasthi A, Jäger A, Strom TB, Oukka M, Kuchroo VK. IL-21 initiates an alternative pathway to induce proinflammatory $\mathrm{T}(\mathrm{H}) 17$ cells. Nature. 2007; 448:484-87.
22. Miller SD, Karpus WJ. Experimental Autoimmune Encephalomyelitis in the Mouse. Curr Protoc Immunol. 2007; Chapter 15:Unit 15.1.

23. Langrish CL, Chen Y, Blumenschein WM, Mattson J, Basham B, Sedgwick JD, McClanahan T, Kastelein RA, Cua DJ. IL-23 drives a pathogenic $\mathrm{T}$ cell population that induces autoimmune inflammation. J Exp Med. 2005; 201:233-40.

24. Park JE, Barbul A. Understanding the role of immune regulation in wound healing. Am J Surg. 2004; 187:11S-16S.

25. Salo M. Effects of anaesthesia and surgery on the immune response. Acta Anaesthesiol Scand. 1992; 36:201-20.

26. Beilin B, Rusabrov Y, Shapira Y, Roytblat L, Greemberg L, Yardeni IZ, Bessler H. Low-dose ketamine affects immune responses in humans during the early postoperative period. Br J Anaesth. 2007; 99:522-27.

27. Waite JC, Skokos D. Th17 Response and Inflammatory Autoimmune Diseases. Int J Inflam. 2012;2012:819467.

28. Yang J, Sundrud MS, Skepner J, Yamagata T. Targeting Th17 cells in autoimmune diseases. Trends Pharmacol Sci. 2014; 35:493-500.

29. Durant L, Watford WT, Ramos HL, Laurence A, Vahedi G, Wei L, Takahashi H, Sun HW, Kanno Y, Powrie F, O'Shea JJ. Diverse targets of the transcription factor STAT3 contribute to $\mathrm{T}$ cell pathogenicity and homeostasis. Immunity. 2010; 32:605-15.

30. Lochmatter C, Fischer R, Charles PD, Yu Z, Powrie F, Kessler BM. Integrative Phosphoproteomics Links IL-23R Signaling with Metabolic Adaptation in Lymphocytes. Sci Rep. 2016; 6:24491.

31. Jain R, Chen Y, Kanno Y, Joyce-Shaikh B, Vahedi G, Hirahara K, Blumenschein WM, Sukumar S, Haines CJ, Sadekova S, McClanahan TK, McGeachy MJ, O'Shea JJ, Cua DJ. Interleukin-23-Induced Transcription Factor Blimp-1 Promotes Pathogenicity of T Helper 17 Cells. Immunity. 2016; 44:131-42.

32. Gooderham M, Posso-De Los Rios CJ, Rubio-Gomez GA, Papp K. Interleukin-17 (IL-17) inhibitors in the treatment of plaque psoriasis: a review. Skin Therapy Lett. 2015; 20:1-5.

33. Leipe J, Grunke M, Dechant C, Reindl C, Kerzendorf U, Schulze-Koops H, Skapenko A. Role of Th17 cells in human autoimmune arthritis. Arthritis Rheum. 2010; 62:2876-85.

34. Lim H, Cho M, Choi G, Na H, Chung Y. Dynamic control of Th2 cell responses by STAT3 during allergic lung inflammation in mice. Int Immunopharmacol. 2015; 28:846-53.

35. Lim H, Kim YU, Sun H, Lee JH, Reynolds JM, Hanabuchi $\mathrm{S}$, Wu H, Teng BB, Chung Y. Proatherogenic conditions promote autoimmune $\mathrm{T}$ helper 17 cell responses in vivo. Immunity. 2014; 40:153-65. 